\title{
Heidegger Leitor de Nietzsche: a Metafísica da Vontade de Potência como Consumaçáo da Metafísica Ocidental
}

\author{
Wanderley J. Ferreira Jr
}

\begin{abstract}
RESUMO: Aspectos básicos da leitura heideggeriana de Nietzsche. As possibilidades e as possíveis distorções operadas por tal interpretaçáo em alguns conceitos fundamentais do pensamento nietzschiano. Num primeiro momento, explicitam-se as duas atitudes de Heidegger diante da história da filosofia e de seus principais pensadores, em momentos diferentes de seu pensamento. Em seguida, analisa-se, com um certo distanciamento crítico, em que sentido, conforme Heidegger, ocorre a consumação da metafísica do sujeito pensante [Descartes] na metafísica da vontade de potência e na ideia de além do homem, em Nietzsche.
\end{abstract}

PALAVRAS-CHAVE: Filosofia. Metafísica. Ciência.

\section{INTRODUÇÁO}

Quais seriam os limites e possibilidades da interpretação/leitura que o filósofo Martin Heidegger (1889-1976) faz de alguns conceitos-chave do pensamento de Nietzsche? Uma interpretaçáo que assume o caráter de uma verdadeira disputa (acerto de contas) (Auseinandersetzung) com Nietzsche, naquilo que esse "último metafísico" teria de essencial. Tomaremos como referências básicas os cursos sobre Nietzsche oferecidos por Heidegger, de 1936 a 1946, e reunidos no $2^{\circ}$ volume da obra intitulada Nietzsche [1962]. (Cf. HEIDEGGER, 1971a).

Seria legítimo, como o faz Heidegger (1971a), considerar Nietzsche um herdeiro da metafísica cartesiana e o lugar de consumação da dominaçáo incondicional da totalidade das coisas pelo pensamento calculador? Heidegger náo hesita em apontar uma metafísica em Nietzsche, na medida em que

\footnotetext{
${ }^{1}$ Graduação, Mestrado e Doutorado em Filosofia - UNICAMP. Professor de Filosofia - Adjunto II Faculdade de Educação - Universidade Federal de Goiás.
} 
ele concebe a totalidade das coisas pela ótica do valor, ou seja, a partir da perspectiva da Vontade de Potência. Ora, mas isso seria suficiente para afirmar, como faz Heidegger, que o filósofo propóe uma "metafísica da vontade de potência”?

Antes de tomar tais questóes como caminhos de investigaçáo, vamos explicitar o caráter do diálogo que Heidegger procurou manter, não apenas com Nietzsche, mas com toda a tradição metafísica do Ocidente, que vai da aurora do pensamento grego ao crepúsculo da era atômica. Talvez assim possamos compreender que a subversão dos significados de conceitos fundamentais do pensamento nietzschiano deve-se à natureza do diálogo que Heidegger procurou manter com a tradição filosófica e a própria compreensão dos conceitos filosóficos como "indicadores formais", os quais não são algo subsistente nem se referem a algo subsistente, mas apontam para a singularidade e contingência da existência fática e histórica que é o homem. Por outro lado, o próprio Nietzsche alertava seus leitores de que seus textos comportam significados múltiplos e até mesmo contraditórios, conforme o tipo de forças e vontade que se apoderam deles.

O fato é que Heidegger, em seu diálogo com a tradição filosófica, adverte-nos de que é necessária uma certa dose de violência no trato com os filósofos. O discurso filosófico comportaria um sentido, um significado, que extrapola a compreensão de seu próprio autor. Compreender os filósofos exigiria, assim, sempre compreendê-los melhor do que eles mesmos e para além deles mesmos (cf. HEIDEGGER, 1971a). Isso faz com que ser fiel não signifique ser necessariamente literal. Devemos ainda considerar que, para Heidegger, pensadores da estatura de Nietzsche são porta-vozes de uma mensagem do Ser cujo mensageiro e destinatário é o próprio homem.

Após explicitar a natureza do diálogo que Heidegger tentou manter com a tradição metafísica, vamos estabelecer o contexto em que se deu o encontro de Heidegger com Nietzsche, para compreender em que sentido, para o filósofo, Nietzsche proporia uma metafísica cujos termos fundamentais seriam: vontade de potência, eterno retorno, niilismo, transvaloração de todos os valores e além do homem. Concluímos essa abordagem de alguns aspectos da leitura heideggeriana de Nietzsche procurando estabelecer os limites e possibilidades de tal leitura, particularmente quando coloca Nietzsche como herdeiro e continuador de uma tradição que ele pretendia superar. 


\section{HeIDEgGer E O CONFRONTO COM A TRADIÇÃo METAFÍsica}

Num primeiro momento de seu confronto com a tradição do pensamento ocidental, Heidegger identifica a ausência de uma explicitação dos modos de ser do ser-aí (Dasein), que nós mesmos somos, a cada momento. O filósofo acusa a tradição metafísica, que vai de Platão a Husserl, passando por Nietzsche, de omitir os modos de ser daquele ente que pergunta pelo ser - o ser-aí (Dasein) que é homem. Na crítica que faz em Ser e Tempo (1927) à ontologia da coisa, em Descartes, Heidegger sustenta que as estruturas ontológicas do Dasein como ser-no-mundo antecedem qualquer intuição a priori de ideias claras e distintas ou qualquer processo de objetificação possível (HEIDEGGER, 1964). Nesse sentido, qualquer tentativa de tematizar ou interpretar o sentido do Ser em geral deveria partir da explicitação dos modos de ser originários do ser-aí que é homem, único que coloca a questão do ser. Nessa primeira fase de seu diálogo com a tradição metafísica, Heidegger considera que esse diálogo deve assumir o caráter de uma destruição ( $A b$ bauen) dessa mesma tradição, sendo esta uma tarefa imposta pela recolocação da questão do ser nos limites do tempo.

A destruição não tem o sentido negativo de arrasar a tradição metafísica. Ela deve definir e circunscrever a tradição em suas possibilidades positivas e isso quer sempre dizer em seus limites. Negativamente, ela não se refere ao passado, ela volta-se para o hoje e os modos vigentes de se tratar a ontologia. Em todo caso, a destruição não se propóe a sepultar o passado em um nada negativo, tendo uma intenção positiva. (HEIDEGGER, 1964, p. 50).

Cabe ressaltar que essa destruição da tradição metafísica não tem um caráter meramente negativo, uma vez que implica um penetrar na história da metafísica, um retorno à essência da Metafísica, ao seu fundamento esquecido, que se encontraria lá, nas experiências originárias dos gregos do ser, do pensar, da linguagem.

No segundo momento de seu confronto com a tradição metafísica, Heidegger denuncia a omissão da diferença ontológica entre Ser e ente. A tradição metafísica ocidental entificou o ser, concebendo-o como fundamento e causa do ente, através das leis da gramática e princípios da lógica, que têm controlado nosso modo de pensar e falar. Enquanto, em Ser e Tempo, o que teria permanecido impensado seriam os modos de ser originários do Dasein, em obras posteriores, o filósofo interpretará essa mesma tradição à luz do pensamento do Ser. Nesse sentido, a história da metafísica não passaria da 
história do esquecimento do Ser. O impensado e não tematizado aqui seria a própria diferença ontológica entre Ser e ente. E, para o filósofo, Nietzsche com sua metafísica da vontade de potência e através da ideia de além-homem (Übermensch) não fez mais que consumar o esquecimento do ser e o domínio incondicional da totalidade do ente por uma subjetividade ávida em dominar e controlar todas as dimensóes do real. Todavia, o que nos interessa aqui é saber se Heidegger em sua "leitura" de Nietzsche levou em consideração algumas das especificidades dos textos desse mestre da suspeita, que escolheu comunicar seu pensamento de forma aforismática - um texto que não aceita uma interpretação que pressupóe um sentido e intenção última do autor, por trás de conceitos purificados de qualquer ambiguidade.

Vejamos como se deu o encontro de Heidegger com Nietzsche. Isso pode nos ajudar a compreender em que sentido, como Aristóteles e Hegel, Heidegger filosofa pensando o já pensado, servindo-se dos autores da tradição filosófica para explicitar e fundamentar suas próprias teses.

\section{O encontro e distanciamento de Nietzsche - PENSAR para além da METAFÍSICA DA VONTADE DE POTÊNCIA}

Desde seu primeiro contato com Nietzsche, que se deu nos anos de formação na Universidade de Freiburgo (1909-1914) e através de alguns fragmentos reunidos sob o título Vontade de potência ${ }^{2}$ (1906), Heidegger faz alusão a uma Vontade de potência própria à filosofia e a qualquer forma de conhecimento objetivável. O filósofo afasta-se de Nietzsche no período de Marburgo (1923-1927), talvez devido à sua apropriação pelas correntes da filosofia da vida [Lebensphilosophie] e a filosofia do valor. Mesmo assim, em um curso de 1925 sobre o Conceito de Tempo, Heidegger faz referência a Nietzsche nos seguintes termos: "A pesquisa filosófica é e permanecerá ateísmo. Pois, ela se pode permitir a arrogância do pensamento... e precisamente em um tal ateísmo a filosofia torna-se, como disse certa vez um grande pensador, a gaia ciência (fröhliche Wissenschaft)". (HEIDEGGER, 1987, p. 15).

O fato é que, somente nos anos 30 e 40, Heidegger irá estabelecer um real enfrentamento com o pensamento nietzschiano, através de cursos e

\footnotetext{
${ }^{2}$ Em algumas passagens de seus cursos sobre Nietzsche, Heidegger já denunciava o caráter duvidoso dessa suposta "obra póstuma" de Nietzsche. Sabemos que, até a década de 1950, essa obra era o instrumento de trabalho disponível aos estudiosos de Nietzsche até ser desmascarada pelas pesquisas de Karl Schlechta, como uma coletânea mal organizada de alguns fragmentos póstumos.
} 
seminários dedicados ao filósofo, que atravessam uma década [1936-1946]. Em tais cursos, Heidegger sempre procurou deixar claro que não se tratava de uma simples exposição das articulaçôes internas do pensamento de Nietzsche, mas de saber a natureza dessa época que constrangeu o filósofo a falar o que falou. Em seu Discurso de Reitorado - Die Selbstbehauptung der deutschen Universität, de 1933 (Cf. HEIDEGGER, 1997), Heidegger deixa uma pista sobre o horizonte em que se movimentará sua interpretação de Nietzsche, ao perguntar se a existência alemã estaria apta a assumir a grande decisão que se impóe diante do veredictum de Nietzsche - "Deus está morto" (Gott ist tot) (Cf. Gaia Ciência, \$125). Essa “boa nova”, observa Heidegger, teria lançado o manto do abandono sobre o homem no mundo dos entes. Com a morte de Deus, caem por terra todos os fundamentos da Metafísica, da Religiáo e da moral. Doravante, não existem mais o Bem, o Belo e a Verdade. Existem apenas, como sempre existiram, perspectivas ou formaçóes de dominação que lutam para se imporem como o lugar da verdade.

Nietzsche seria, portanto, o signo do fim de uma época e, ao mesmo tempo, arauto de um novo começo. Seu dizer e seu pensar se constituiriam no ponto de partida para uma nova época do pensamento do Ser. Em O que significa pensar? (1954) (Was heisst Denken? -1951/52), Heidegger admite que Nietzsche, mais que qualquer outro pensador, via e tomava como tarefa a necessidade de ultrapassar o seu tempo. Talvez, ele tenha sido o primeiro a ver o perigo que se avizinhava nessa incondicional dominação do homem sobre o globo terrestre, o primeiro a colocar questóes tais como: estaria o homem preparado para exercer seu domínio incondicional sobre a terra? (HEIDEGGER, 1954, p. 53).

Entretanto, em sua obra Nietzsche, mais precisamente na primeira frase do capítulo VI, intitulado Nietzsches Metaphysik (1940), Heidegger afirmava que o pensamento nietzschiano possui a mesma natureza metafísica do pensamento ocidental que se desenvolveu desde Platão. Nietzsche, porém, seria aquele pensador no qual essa tradição teria realizado suas últimas possibilidades na metafísica da vontade de potência. (Cf. HEIDEGGER, 1971).

Heidegger não apenas afirma possuir Nietzsche uma metafísica, mas aponta seus conceitos fundamentais: vontade de potência, niilismo, eterno retorno do mesmo, Além-do-homem e transvaloração de todos os valores (justiça). Vontade de potência seria a expressáo para o ser do ente enquanto tal, ou seja, para a essência do ente. Niilismo é o nome para a história da verdade do ente assim determinada. Eterno retorno do mesmo designaria o modo como o ente 
é em sua totalidade, a existência do ente. O Além-do-homem, por sua vez, caracterizaria a humanidade exigida por essa totalidade do ente. Justiça é a essência da verdade do ente enquanto Vontade de potência (HEIDEGGER, 1971, p. 260). Esses cinco termos seriam, segundo Heidegger, as faces ou máscaras em que aparece a metafísica de Nietzsche. Na realidade, a metafísica da vontade de potência não representaria uma ruptura, como pretendia Nietzsche, com as filosofias do sujeito, mas representa sua consumação. O Übermensch, o além-do-homem, seria a radicalização e absolutização da hegemonia do cogito cartesiano. Descartes e Nietzsche seriam, assim, momentos de um mesmo processo de objetificaçáo incondicionada da totalidade do ente que aprofunda o esquecimento do ser.

Para Heidegger, a metafísica do sujeito pensante encontra o lugar de sua consumação na metafísica da Vontade de Potência e na ideia de alémhomem em Nietzsche. Ora, contudo, não podemos negligenciar o fato de que a proposta de Nietzsche de uma transvaloração de todos os valores coloca sob suspeita a superficialidade da consciência - esse epifenômeno que insiste em continuar a determinar a vontade e os instintos. Essa denúncia da superficialidade da consciência já estaria presente na distinção apolíneo e dionisíaco, que Nietzsche elabora na Origem da tragédia do espírito da música Grega [1871].

Assim, a crítica de Nietzsche ao cogito cartesiano insere-se no âmbito de sua crítica à razão ocidental, cuja hegemonia teria começado com Sócrates, esse grande sedutor. Sócrates seria o arauto da ordem e clareza racional apolínea, da racionalidade separada e desraigada de sua relação constitutiva com o dionisíaco - o mundo da vida imediata, das pulsóes, da alternância irremediável do nascimento e morte, dor e prazer, sofrimento e alegria. Em Humano, demasiado bumano, Nietzsche insiste em afirmar que nossas vivências e experiências conscientes se baseiam naquilo para o qual temos uma linguagem, nomes e possibilidades de descrição na língua socialmente imposta. Essa denúncia do caráter superficial da autoconsciência, da razão, é sempre acompanhada de um questionamento da experiência da verdade limitada à razão e leis lógicas e à diluição mais ampla do ser como fundamento - expressa na sentença Deus está morto. (NIETZSCHE, 1987).

Em Verdade e Mentira no sentido extramoral, Nietzsche deixa claro que a constituição do mundo da verdade e da lógica se fundamenta na obrigação de mentir segundo regras socialmente fixadas, conforme um sistema de metáforas aceitas ou impostas pela sociedade. $\mathrm{O}$ mundo objetivo da consciência tende a 
configurar-se progressivamente como mundo da consciência compartilhada, produto da sociedade através dos condicionamentos impostos pela linguagem. (Cf. NIETZSCHE, 1987). Mas não apenas os conteúdos de nossa consciência [representações, ideias] que concernem ao mundo fenomênico são ficções reguladas pelas convençôes sociais: também a imagem que o sujeito faz de si mesmo, como eu psicológico ou epistêmico. Nossa autoconsciência é a imagem que temos de nós mesmos tirada da imagem que os outros têm de nós e que nós adotamos por uma questáo de segurança - por defesa, temos que introjetar o modo segundo o qual nos veem os demais.

\begin{abstract}
A maior parte dos homens, independente do que pensam e do que diga seu egoísmo, não fazem nada ao longo de sua vida por seu ego, mas apenas pelo fantasma de seu ego que se formou na cabeça de quem os rodeiam... Todos vivem em uma nuvem de opinióes impessoais e semipessoais. Todos esses homens que não se conhecem entre si, crêem nesse ser abstrato que chamam homem, que é precisamente apenas o resultado daquelas opinióes pessoais, difusas e envolventes, que se desenvolvem e vivem com toda a independência dos indivíduos. (NIETZSCHE, 1987, Aurora, af. 105).
\end{abstract}

Para Nietzsche, a superficialidade da consciência, uma vez desmascarada, não abre a via de nenhuma outra fundamentação mais segura. A descoberta de que a consciência, a razão, não pode ser fundamento, revela a impossibilidade de qualquer fundamentação última ou certeza, o que nos conduziria para uma nova concepção acerca da experiência da verdade e do próprio Ser, no âmbito de um perspectivismo no qual as noçóes de Vontade de Potência e eterno retorno desempenham um papel fundamental.

Ora, a partir das consideraçóes precedentes, podemos considerar que a leitura do além-do-homem, feita por Heidegger, colocando-o como consumação da subjetividade cartesiana e seu ideal de dominação incondicional sobre a totalidade das coisas, negligencia o fato de que o além-homem, em Nietzsche, não é uma forma potenciada da subjetividade nascida com Descartes. Em uma realidade que é essencialmente vontade de Poder e se manifesta como eterno retorno, não há lugar para qualquer estabilidade e objetividade baseada em conceitos e valores universais e necessários. A única positividade parece ser a capacidade desse homem, que já não é mais sujeito puro cartesiano, de negarse a si mesmo como sujeito, indo além de toda exigência de autoconservação e certeza de si, na direção de uma experiência sem limites, fazendo de si mesmo um campo de batalha, pensando até mesmo contra si. 
A Vontade de Potência diria o que o ente é quanto à sua constituição, ou seja, quanto à sua essência. E o eterno retorno do mesmo diria o como é necessário que seja o ente o qual tem como essência a Vontade de Potência - uma Vontade que, segundo Heidegger, já estaria presente na vontade de certeza que perpassaria a metafísica moderna desde Descartes. Heidegger aqui parece ignorar o fato de a crítica nietzschiana dirigir-se a todo sistema da moral ocidental que pretende fundar-se sobre um consenso tradicional e na justificação das açốes pelo apelo à consciência do Sujeito pensante, enquanto sujeito consciente de si.

Heidegger até reconhece que o impulso inicial dos tempos modernos dado por Descartes e o início da história de seu acabamento com Nietzsche são extremamente diferentes. Contudo, essa diferença exterior atestaria que há no fundo uma identidade essencial entre esses dois pensamentos. É somente sobre o terreno da metafísica cartesiana que Nietzsche pôde voltar seu pensamento contra Descartes, levando ao seu acabamento a posição metafísica cartesiana na metafísica da Vontade de Potência. (Cf. HEIDEGGER, 1971, p. 150). Contudo, o fato que não pode ser negligenciado por nenhum intérprete de Nietzsche é que este, apesar de pedir a seus leitores um certo direito ao contrassenso, sempre se manteve fiel ao seu projeto de uma transvaloraçáo de todos os valores, a partir da qual o filósofo denuncia que a consciência de si cartesiana é falsa e que sua evidência é uma ilusão. O cogito cartesiano, enquanto fundamento último que garante a certeza no conhecimento e a segurança no controle do ente em sua totalidade, é destronado quando se descobre, com Nietzsche, o quáo lamentável, sem finalidade e gratuito é o intelecto humano dentro do cosmos:

Houve eternidades em que ele náo estava, quando de novo ele estiver passado, nada terá acontecido...não há para aquele intelecto humano nenhuma missão mais vasta, que conduzisse além da vida humana... ele é humano... O intelecto como meio de conservação do indivíduo desdobra suas forças mestras no disfarce; pois este é o meio pelo qual os indivíduos mais fracos, menos robustos, se conservam... No homem essa arte do disfarce chega ao seu ápice... que quase nada é mais inconcebível do que como pôde aparecer entre os homens um honesto e puro impulso à verdade. (NIETZSCHE, 1987, p. 45-46).

O suposto Sujeito pensante cartesiano, que funda toda certeza na certeza de si, encontra-se habitado, não por uma força racional e livre, mas por forças irracionais, inconscientes. Nâo há como negar, portanto, que a denúncia que Nietzsche faz do homem visa a arrancá-lo de seu sonho narcisista, 
revelando-lhe sua verdadeira face, desmascarando a ilusão da boa consciência e seus valores. $\mathrm{O}$ que há é uma intransponível distância entre o homem e a natureza, distância que deve ser assumida com o dizer sim à vida, mesmo em seus momentos mais perigosos e dolorosos.

$\mathrm{Na}$ concepção de Heidegger, contudo, a subjetividade que surge com a metafísica cartesiana atinge suas últimas possibilidades como subjetividade da Vontade de Potência, que, por sua vez, vai exigir um tipo específico de homem que esteja muito além e acima desse homem gregário do presente. "Não mais a humanidade, mas o Além-do-homem é o objetivo" (NIETZSCHE 29, fr. 100 apud HEIDEGGER, 1971, p. 243). A vontade quer o Além-do-homem na medida em que somente assim ela suporta o mais pesado dos fardos o eterno retorno do mesmo. Ora, pergunta Heidegger, quem é esse homem em vista do qual e pelo qual o ente é humanizado? Sem dúvida, observa o filósofo, a totalidade do ente é reduzida à subjetividade, mas à subjetividade acabada da Vontade de Potência, que autoriza o ente a apresentar-se enquanto tal. Heidegger esclarece, no entanto, que essa soberania do homem como mestre e senhor não é aqui adquirida mediante o emprego da violência bruta contra as coisas e os outros viventes. Tornar-se mestre, nesse sentido, significa primeiramente subordinar-se a si mesmo ao comando que emana da essência do Poder mesmo: "Desde que a animalidade do homem é conduzida à Vontade de Potência como a essência própria dessa animalidade, o homem torna-se assim o animal firmemente estabelecido." (HEIDEGGER, 1971, p. 245-246).

Ora, para Heidegger, a organização e planificação planetária de toda praxis humana náo seria senão o modo como a vontade de Potência, transformada numa vontade de vontade, mantém-se mediante seu incessante superar a si mesma. A técnica seria a forma fundamental sob a qual a vontade de vontade aparece e instala-se ela mesma na não historicidade do mundo da metafísica acabada (HEIDEGGER, 1958, p. 92).

Essa apropriação das coisas humanas feita por essa vontade de vontade desvia o homem da possibilidade de superar o esquecimento do Ser, pois, na medida em que devasta a terra, essa vontade gera um pathos no âmbito do qual paira uma aparente ausência de angústia, que não é senão a forma mais extrema de angústia, infortúnio e indigência. A ausência de angústia, constata Heidegger, está justamente no fato de o homem alimentar a ilusão de que domina o real, além de saber o que é a verdade, sem que se tenha necessidade de saber onde reside a verdade. 


\section{AfINAL, PODE-SE FALAR DE UMA METAFÍSICA DA VONTADE POTÊNCIA EM NIETZSCHE?}

Para Heidegger, a visão nietzschiana do caráter da totalidade do ente como Vontade de Potência não passa da "[...] experiência fundamental de um pensador [...] que é constrangido a pronunciar isso: [...] Que o ente é, tal como é e naquilo que é, Vontade de Potência." (HEIDEGGER, 1971, p. 35). Heidegger esclarece que vontade, na expressão vontade de potência, não é uma mera faculdade humana do querer que aspira qualquer coisa. E poder não deve ser confundido com o exercício cotidiano da violência, como um ato voluntarioso de um indivíduo poderoso. A expressão Vontade de Potência, compreendida de forma distorcida, expressaria um sentimento de deficiência, na medida em que ela não teria aquilo que quer - o poder. Heidegger considera isso uma deformaçáo do sentido autêntico de um dos termos fundamentais do que ele chama a metafísica de Nietzsche. (Cf. HEIDEGGER, 1971).

Müller-Lauter ressalta que a própria interpretação heideggeriana da Vontade de Potência como princípio metafísico em Nietzsche seria equivocada, já que Heidegger concebe uma unidade na Vontade de Potência a qual se manteria através da constante superação de si, o que, por sua vez, exigiria que a totalidade do ente se manifestasse como eterno retorno do mesmo. De acordo com Heidegger, Nietzsche acaba se pronunciando sobre a totalidade do ente, ao conceber sua essência como Vontade de Potência e sua existência como eterno retorno do mesmo. Contudo, Müller-Lauter entende que o todo em Nietzsche só se dá como caos. O ente enquanto tal não é mais fixável. Não teria, portanto, sentido falar de qualquer fundamento do ente em Nietzsche. (MÜLLER-LAUTER, 1997, p. 70).

Segundo Heidegger, um primeiro olhar essencial ao conteúdo da expressão Vontade de Potência teria sido lançado por Nietzsche, na segunda parte do seu Zaratustra, na passagem intitulada "Da superação de si”. Ali, o profeta do Além-do-homem sentencia:

Mas para entenderes minha palavra de Bem e de Mal: para isso quero dizervos ainda minha palavra da vida, e do modo de todo vivente. [...] Mas onde encontrei vida, ali ouvi falar a obediência. Todo vivente é um obediente. E isto em segundo lugar: manda-se naquele que não pode obedecer a si próprio. Tal é o modo do vivente. [...] Onde encontrei vida, ali encontrei Vontade de Potência ; e ainda na vontade do servo encontrei a vontade de ser senhor. (NIETZSCHE, 1983, p. 238, apud HEIDEGGER, 1971, p. 264-265). 
Tudo que é vida é Vontade de Potência, ou seja, onde há vida, há vontade de conservação e engrandecimento de vida. E tudo isso, que é apenas conservação da vida, não passa de decadência e declínio da Vontade de Potência, que é "[...] vontade de durar, de crescer, de vencer, de estender e intensificar a vida. É o mais forte de todos os instintos, o que dirige a evolução orgânica”. (NIETZSCHE, 1985, p. 63). Segundo Heidegger, é a totalidade do ente que é constituída e mantida por essa vontade que sujeita tudo ao ciclo infindável do nascer e do perecer, enfim, o próprio mundo é em sua essência Vontade de Potência.

Este mundo é um monstro de força sem começo nem fim, uma quantidade de força brônzea que não se torna nem maior nem menor, que não se consome, mas só se transforma, imutável no seu conjunto [...] Força em toda parte, é jogo de forças e ondas de forças, uno e múltiplo simultaneamente acumulando-se aqui, enquanto se reduz ali, um mar de forças agitadas que provocam sua própria tempestade, transformando-se eternamente num eterno vaivém, com imensos anos de retorno [...]... quereis um nome para esse universo, uma solução para todos os enigmas? Uma luz até para vós, os mais ocultos, os mais fortes, os mais intrépidos de todos os espíritos, para vós homens da meia noite? Este mundo é o mundo da Vontade de Potência e nada mais! E vós também sois esta Vontade de Potência e nada mais... (NIETZSCHE, 1985, p. 290)

Heidegger acredita que, a partir da relação essencial entre Vontade de Potência e eterno retorno do mesmo, podemos compreender em que medida a vontade de vontade, a qual impulsiona o poder desafiador da técnica, não tem fim algum senão sua própria intensificação. Isso só é possível porque o ser do ente é concebido como Vontade de Potência, que em seu constante ultrapassamento de si exige o eterno retorno do mesmo. Assim, segundo Heidegger, Nietzsche não marcaria o ponto de enfraquecimento ou de superação da metafísica e, consequentemente, da própria era da técnica. Seu pensamento, na verdade, representaria o aprofundamento e o acabamento do projeto da metafísica de um incondicional controle sobre o real. A totalidade do ente que se manifesta como Vontade de Potência faz com que essa totalidade não passe de um devir, sem início, sem fim e unidade. Esse devir expressaria o movimento circular de intensificação do Poder: eis porque o caráter fundamental da Vontade de Potência se determina enquanto Eterno Retorno do Mesmo. 


\section{CONCLUSÁo}

Certamente, para os mais ortodoxos, a interpretaçáo heideggeriana violenta em muitos aspectos o pensamento de Nietzsche. Entretanto, podemos apontar alguns pontos de consenso entre ambos:

1. Heidegger partilha com Nietzsche o sentimento de que o niilismo não é um fenômeno recente ou tipicamente moderno, e que o reino do niilismo começa com o dualismo platônico entre mundo sensível, objeto de opinião e mundo inteligível, suposto lugar da verdade.

2. Esse reino do niilismo conhece seu apogeu, quando o horizonte que separava o mundo verdadeiro do mundo simplesmente aparente desaparece, fazendo com que o mundo até entâo considerado verdadeiro se transforme numa fábula.

É certo que Nietzsche teria precipitado a crise da metafísica, ao explicitar o elemento diferencial que estaria na origem de nossas avaliaçóes e na origem da noção de verdade, sem se contentar em simplesmente inverter a hierarquia platônica do sensível e do inteligível, de ser e vir-a-ser. Contudo, ele teria omitido a questão da essência da verdade, não percebendo que sua própria crítica à noção de verdade enquanto estimativa de valor pressupóe uma verdade cuja essência seria a adequação, a conformidade (o $\mu \mathrm{o} \omega \sigma \imath \varsigma)$. Nesse sentido, podemos considerar, com Heidegger, que Nietzsche teria submetido o subjetivismo e o racionalismo cartesiano a uma crítica feroz, mas ele não teria percebido que o ego volo (Eu quero) tem como precursor o ego cogito (Eu penso) cartesiano. Apesar de reconhecer que a origem do niilismo estaria no estabelecimento de certos valores transcendentes, Nietzsche acredita que certos valores, todavia, podem ser salvos. Ao pensar sob o ponto de vista do valor, Nietzsche obscurece a própria essência do niilismo, não percebendo que o niilismo consiste no fato de, no curso da história Ocidental, o ser ter sido esquecido, tornando-se, como dirá o próprio Nietzsche, um vapor (Cf. HEIDEGGER, 1971).

Certamente a leitura que Heidegger faz de Nietzsche comporta um determinado número de ambiguidades que se expressariam pelo viés de duas questóes: como seria possível que o pensamento de Nietzsche implique o fim da metafísica, sendo ao mesmo tempo uma metafísica? E como se pode dizer que Nietzsche é o último metafísico e considerá-lo como um metafísico entre outros? Podemos considerar também que é, no mínimo, temerária a tese heideggeriana que considera a Vontade de Potência e o eterno retorno do 
mesmo na esteira da metafísica escolástica, ao afirmar a correlação de ambos os termos com os termos essentia e existentia. Isso significaria que a Vontade de Potência e o eterno retorno do mesmo sejam respostas à antiga questão ontológica colocada pelos gregos: que é o ente?

No entanto, apesar de todos os equívocos, ambiguidades e possíveis distorçôes, o que importa é que, da leitura heideggeriana, pode emergir um Nietzsche que não seja apenas o herdeiro e continuador da tradição metafísica iniciada com Platão, mas, quem sabe, o ponto de partida de um pensamento originário apto a pensar e ultrapassar o domínio planetário da técnica. Quanto à questão de saber se o pensar e o dizer de pensadores como Nietzsche e Heidegger desvelam alguma dimensão da verdade e do próprio Ser, deixamos a resposta com o próprio Nietzsche:

Não nos é lícito nem equivocarmos, nem apenas encontrar a verdade. Antes porém, com a necessidade que uma árvore oferece seus frutos, brotam de nós nossos pensamentos, nossos valores, nossos sim e nossos nãos, nossas perguntas e nossas dúvidas - ... Tudo isto como testemunho de uma única vontade, de uma única saúde, de um único reino terreno, de um único sol. Se esses frutos desgostaram alguns, mas que importa isto às árvores. Que nos importa isso a nós, os filósofos... (NIETZSCHE, 1985, \$2, p. 18).

Heidegger, de seu lado, certa vez disse que questóes não se dão à maneira de coisas que estão simplesmente aí. "Questôes são e são apenas enquanto se investigam...” (HEIDEGGER, 1958, p. 32). Questóes, portanto, só existem na medida em que se tornarem caminhos em direção àquilo que merece ser questionado: o sentido e a verdade do Ser nos limites do tempo. Para Heidegger, essa é a questão-guia da filosofia. Todas as demais questôes levantadas ao longo de seu diálogo com a tradição metafísica estão envolvidas e se nutrem do pathos dessa questão fundamental.

Ora, que originalidade haveria em recolocar uma questão tão antiga quanto a questão do Ser e numa época que já vive a falência dos grandes sistemas metafísicos e das metanarrativas de caráter soteriológico? Que sentido teria a questão do Ser em um tempo indigente, que promove a massificação do homem, a fuga dos deuses, a devastação da terra e que não é capaz de pensar sua própria indigência enquanto tal? Sob a sombra da morte de Deus, que sentido teria falar em Ser, Verdade, Unidade, Finalidade e Salvação? Entretanto, o filósofo pergunta novamente pelo sentido do Ser e pela sua relação originária e essencial com o homem mediante o pensar, o falar e o 
próprio tempo. Evidentemente, uma tal tarefa comporta grandes equívocos e erros. Mesmo porque, "[...] quem pensa profundamente, deve profundamente errar” (HEIDEGGER, 1966, p. 45). É preciso não esquecer ainda que Heidegger jamais pensa sobre alguma coisa ou pensador, ele pensa alguma coisa com o pensador, não com o objetivo de descobrir um solo último e seguro, mas na tentativa de abrir caminhos, propor tarefas. Esses caminhos, muitas vezes, como as sendas nas florestas, não levam a lugar algum. Porém, o que importa aqui é o estar a caminho na companhia de pensadores com os quais ainda se pode aprender a pensar.

FERREIRA JUNIOR, Wanderley J. Heidegger reader of Nietzsche: a metaphysics of the will power as a consummation of Western metaphysics. Trans/Form/Ação, Marília, v. 36, n. 1, p. 101-116, Jan./Abril, 2013.

\begin{abstract}
This article presents the basic aspects of Heidegger's reading of Nietzsche and the possibilities and possible distortions of this interpretation with regard to some basic concepts of Nietzschean thought. First, we make explicit two different attitudes of Heidegger toward the history of philosophy and its leading thinkers, as found in different periods of Heidegger's thought. Secondly we analyze, with a certain critical distance, in what sense, according to Heidegger, metaphysics is the consummation of the thinking subject (Descartes) in the metaphysics of the will to power and the idea of beyond man in Nietzsche.
\end{abstract}

KEYWORDS: Philosophy. Metaphysical science.

\title{
REFERÊNCIAS
}

BIRAULT, Henri. Heidegger et l'experience de la pensée. Paris: Gallimard, 1978.

DELEUZE, Giles. Pensamento Nômade. In: MARTON, Scarlett (Org.). Nietzsche Hoje? São Paulo: Brasiliense, 1985.

FINK, Eugene. Nova Experiência do mundo em Nietzsche. In: MARTON, Scarlett (Org.). Nietzsche Hoje? São Paulo: Brasiliense, 1985.

HEIDEGGER, Martin. A auto-afirmação da Universidade alemã. Trad. Fausto Castilho. Curitiba: Secretaria de Estado da Cultura, 1997. Was heisst denken. Tübingen: Max Niemeyer, 1954. 
Wer ist Nietzsches Zarathustra? In: Vorträge und Auftsätze. Neske: Pfullingen, 1954. . Essais et Conférences. Trad. A . Preau. Paris: Gallimard, 1958. . Introdução à metafísica. Rio de Janeiro: Tempo Brasileiro, 1969. . L'etre et le Temps. Tradução: R. Boehm et A . de Waelhens. Paris: Gallimard, 1964. 1966. . L'experience de la pensée. In: Questions III. Tradução: A . Preau. Paris: Gallimard, . Nietzsche v. II. Tradução: P. Klossowski. Paris: Gallimard, 1971. . O fim da Filosofia e a tarefa do pensamento . São Paulo: Abril Cultural, 1987.

MARTON, Scarlett (Org.). Nietzsche Hoje? São Paulo: Brasiliense, 1985.

. Nietzsche - Das forças cósmicas aos valores humanos. São Paulo: Brasiliense, 1990. MÜllER-LAUTER, Wolfgang. A doutrina da Vontade de Potência em Nietzsche. Trad. Oswaldo Giacóia. São Paulo: Annablume, 1997.

NIETZSCHE, Friedrich. Sämtliche Werke. Kritische Studienausgabe. Hrsg G.Colli und M. Montinari. Berlin/Munique: Walter de Gruyter/DTV, 1988. Assim falou Zaratustra - um livro para todos e para ninguém. Tradução: Trad. Mário da Silva. Rio de Janeiro: Civilização Brasileira, 1983.

. Obras Incompletas. São Paulo: Abril Cultural, 1987.

. Genealogía de la Moral. Tradução: Trad. Andrés Sanchez Pascual. Madrid: Alianza, 1994.

VATTIMO, Gianni Más allá del sujeto. Nietzsche, Heidegger y la hermenéutica. Trad. de J. C. Gentille Vitale. Barcelona: Paidós, 1989.

Recebido em: 06.05.2012

Aceito em: 07.06.2012 
FERREIRA JUNIOR., W. J. 